\title{
Racionalidades de gobierno en medio y a través de la guerra reciente en Colombia ${ }^{1}$
}

\author{
Darío Muñoz-Onofre ${ }^{2}$ \\ Instituto de Filosofia y Ciencias Humanas (IFCH), Universidad \\ Estatal de Campinas (UNICAMP), Brasil \\ darmuz@yahoo.com \\ Recibido: 9 de agosto de 2016 \\ Aceptado: 12 de octubre de 2017 \\ Disponible en línea: 30 de junio de 2018
}

1 El artículo presenta resultados de la investigación "Gobernados en medio (y a través) de la guerra. Gubernamentalidad bélica en Colombia (2001-2010)", realizada por el autor entre 2009 y 2011, con el apoyo del Programa de Formación en Posgrados para docentes de la Pontificia Universidad Javeriana de Bogotá (PUJ) y adscrita al grupo de investigación Lazos Sociales y Culturas de Paz de la misma universidad. También presenta avances de la investigación doctoral en curso: "Prácticas culturales de transfiguración de la guerra en Colombia (2001-2010)", auspiciada por el Programa Doctorados en el Exterior de Colciencias.

2 Psicólogo y Magíster en Estudios Culturales, Pontificia Universidad Javeriana (Colombia). Doctorando en Ciencias Sociales de la Universidad Estatal de Campinas (Brasil). Becario de Colciencias. 


\title{
Racionalidades de gobierno en medio y a través de la guerra reciente en Colombia
}

\section{Resumen}

Los resultados de investigación que presento en este artículo remiten al análisis de cuatro racionalidades de gobierno que se desplegaron en Colombia con la radicalización de la guerra en 2002 y durante el resto de la década: polarizar el conflicto, garantizar la soberanía, gestionar una población favorable a la guerra y asegurar la inversión transnacional. A partir de un heterogéneo archivo de prácticas históricas, que no se centran exclusivamente en el Estado, reconozco los mecanismos de normalización de la guerra y de gestión de su aceptabilidad en la opinión pública, como una singular forma de gobierno. Finalmente, sitúo los alcances de este análisis y propongo algunos de los desafíos que actualmente enfrentamos en el país para avanzar en la finalización definitiva de la guerra.

Palabras clave: guerra en Colombia; gubernamentalidad; seguridad democrática; racionalidades politicas; normalización; Farc

\section{Rationalities of government in the midst and through the recent war in Colombia}

\begin{abstract}
The research results that I present in this article refer to the analysis of four rationalities of government that were deployed in Colombia with the radicalization of the war in 2002 and during the rest of the decade: polarizing the conflict, guaranteeing sovereignty, managing a population favorable to war, and securing transnational investment. I recognize the normalization mechanisms of war and the management of its acceptability in public opinion, as a singular form of government based on a heterogeneous archive of historical practices, which do not focus exclusively on the State. Finally, I define the scopes of this analysis and propose some of the challenges we currently face in the country as to advance in the final end to the war.
\end{abstract}

Keywords: war in Colombia; governmentality; democratic security; political rationalities; standardization; Farc

\section{Racionalidades de governo em meio e através da guerra recente na Colômbia}

\section{Resumo}

Os resultados de pesquisa que apresento neste artigo remitem para a análise de quatro racionalidades de governo que foram implantadas na Colômbia com a radicalização da guerra em 2002 e durante o resto da década: polarizar o conflito, garantir a soberania, gerir uma população favorável à guerra e assegurar o investimento transnacional. A partir de um heterogêneo arquivo de práticas históricas, que não são centradas exclusivamente no Estado, reconheço os mecanismos de normalização da guerra e da gestão de sua aceitabilidade na opinião pública, como uma singular forma de governo. Por fim, coloco o escopo desta análise e proponho alguns dos desafios que atualmente enfrentamos no país para avançar na finalização definitiva da guerra.

Palavras-chave: guerra na Colômbia; governamentalidade; seguridad democrática (segurança democrática); racionalidades políticas; normalização; Farc 
La investigación de la que se deriva este artículo se enmarca en los acontecimientos ocurridos en Colombia durante el periodo comprendido entre los años 2002 y 2010. El inicio de este periodo estuvo marcado por la reactivación e intensificación de la guerra, después del fracaso definitivo en 2002 de los diálogos de paz entre el Gobierno nacional, presidido en ese momento por Andrés Pastrana, y las Fuerzas Armadas Revolucionarias de Colombia (Farc). La investigación muestra cómo en medio y a través de la reactivación de la guerra y de su perpetuación se gestó una modalidad particular de gobierno de la población colombiana. Esta modalidad gestionó una opinión pública favorable a la confrontación militar, normalizó la guerra y la convirtió en el centro de la práctica gubernamental, hasta el punto de que sectores amplios de población experimentaron adhesión a la empresa bélica e, incluso, llegaron a convertirla en el principal motivo de su identidad nacional y el centro de su orgullo patrio.

La investigación aborda la guerra y la gubernamentalidad a partir del análisis histórico de su implicación recíproca: analiza la guerra como una modalidad gubernamental y, simultáneamente, analiza las prácticas de gobierno como mecanismo de reactivación, perpetuación y normalización de la guerra. Con ello, apunta a un doble propósito: interrogar los procedimientos gubernamentales puestos en práctica para reactivar y perpetuar la guerra en Colombia durante el periodo investigado, y poner en evidencia cómo la guerra así gestionada funcionó como una modalidad específica de gobierno de la población.

Esta es una manera diferente de abordar la guerra y la gubernamentalidad $^{3}$ en el país: por una parte, de la guerra no busca caracterizar los factores estructurales que la producen o analizar las motivaciones políticas e ideológicas de los actores armados enfrentados en ella. Tampoco adopta para su análisis la perspectiva del

\footnotetext{
Inspirado en Foucault (2006, 2007, 2009), entiendo la gubernamentalidad como un conjunto heterogéneo de prácticas y procedimientos que modulan creencias, expectativas, deseos, opiniones y comportamientos en una población dada, a partir de los fines, los medios y las estrategias que organizan dichos procedimientos y prácticas. A partir de mi investigación, considero que la gubernamentalidad es un prisma que aporta nuevas comprensiones al análisis de la guerra y las racionalidades que la dinamizan.
} 
Derecho Internacional Humanitario, pero no por considerarla irrelevante o innecesaria, sino porque destaca una dimensión inadvertida o poco estudiada de la guerra en Colombia. Por otra parte, no reduce la gubernamentalidad al funcionamiento de las instituciones del Estado y la dinámica de los partidos políticos, ni se enfoca en realizar un balance de las metas de gobierno para formular mejores prácticas administrativas, ni en evaluar las políticas públicas para ajustarlas y cumplir mejor los objetivos que se proponen.

Si bien es un abordaje que contempla el análisis de programas de gobierno y políticas públicas, no se limita a ello porque reconoce que la gubernamentalidad bélica también se juega en prácticas heterogéneas como la gestión de opinión pública a través de las industrias de la información y el entretenimiento, la movilización política en redes sociales e iniciativas ciudadanas, y la producción global y local de tecnologías de seguridad.

\section{Heterogeneidad del archivo y especificidad del análisis}

El archivo ${ }^{4}$ de investigación está compuesto por prácticas heterogéneas que se desplegaron durante el periodo estudiado. Entre ellas, en primer lugar, se encuentran las políticas oficiales y los documentos extraoficiales publicados a partir de 2002, que prefiguraron la Política de Defensa y Seguridad "democrática" 5 (PDSD) (Presidencia de la República, Ministerio de Defensa Nacional, 2003). El esbozo inicial de las estrategias para reactivar la guerra y gobernar en medio de ella fue publicado en mayo de ese año en forma de manifiesto (Uribe, 2002). Este fue la base de la PDSD, de las políticas

4 Inspirado en la perspectiva genealógica de Foucault (1992), entiendo que el archivo no es un lugar donde residen las fuentes empíricas que se consultan para fines investigativos, sino el conjunto de prácticas (discursivas y no discursivas) que el investigador identifica y analiza como constituyentes de un cierto modo de gubernamentalidad.

5 Utilizo comillas para desvirtuar el uso de la palabra democrática en las políticas de seguridad, porque considero que ello fue una estrategia retórica para promover la aceptación pública de esas políticas y velar su modo de funcionamiento estrictamente bélico. Mis publicaciones (Muñoz, 2012 y 2014; Muñoz-Onofre, 2015) son mi propia táctica de resistencia frente a esa estrategia de normalización de la guerra; en ellas busco reconocer críticamente la red de prácticas culturales y racionalidades de gobierno que articularon históricamente la guerra y contribuyeron a su normalización. 
de seguridad incluidas en los planes de desarrollo nacional 20022006 (DNP, 2003) y 2006-2010 (DNP, 2007), y de la Política de Consolidación de la Seguridad Democrática (DNP, CONPES, 2007). Además, se encuentran los decretos presidenciales que establecieron las condiciones normativas, las fuentes de financiación y el estado de excepción para garantizar el éxito de la empresa bélica.

No obstante, el archivo excede las políticas oficiales y los documentos extraoficiales, ya que también otras prácticas históricamente específicas contribuyeron a configurar las racionalidades. Por ello, en segundo lugar, se encuentran la estrategia y el discurso del nuevo orden geopolítico internacional, marcado por la "guerra global contra el terrorismo", tras los ataques del 11 de septiembre de 2001 en Estados Unidos (ONU, 2001; Bush, 2002; Comunidad Andina, 2002; OEA, 2002). En tercer lugar, se encuentran variados procedimientos de gestión de opinión pública, tales como la campaña "Vive Colombia, viaja por ella”, dirigida a la recuperación de la soberanía nacional mediante la incentivación del turismo (Presidencia de la República, Ministerio de Comercio, Industria y Comercio, 2002); la política visual de la revista Semana (2002) que promovió en la opinión pública la percepción de fracaso de los diálogos con las Farc y la aceptación de la guerra total; y la campaña publicitaria dirigida a mejorar la imagen pública de las Fuerzas Militares del Estado, a través de la exaltación del heroísmo patrio de sus soldados (Ejército Nacional de Colombia, s.f.).

El análisis sobre el archivo descrito se inspira en Foucault (1991): descarta que las racionalidades sean el resultado del acto fundador de algún sujeto y, por el contrario, reconoce su especificidad e inmanencia, así como su carácter histórico y fragmentario. Asimismo, no entiende la racionalidad en términos de la supuesta oposición con la irracionalidad, de modo que reconoce la racionalidad de las prácticas bélicas, las cuales usualmente son vistas como irracionales.

En consecuencia, con respecto a las prácticas mencionadas, el análisis reconoce: los fines que las orientan, los medios y objetivos que trazan para alcanzar dichos fines, los procedimientos que esta- 
blecen como curso de acción, los efectos que producen por la aplicación de tales procedimientos, ${ }^{6}$ las amenazas y los enemigos que refieren, las estrategias para prevenir amenazas y combatir enemigos, el lugar y la función que le asignan a la población en términos de fines, objetivos, amenazas y estrategias, así como las medidas previstas para garantizar el cumplimiento de dicha asignación y, finalmente, los discursos que justifican la guerra y anteponen su inevitabilidad como forma de gobierno.

\section{Polarizar el conflicto}

El fin de esta racionalidad fue reactivar y radicalizar el conflicto armado, y sus objetivos consistieron en identificar el enemigo interno y aislarlo social y políticamente, así como construir y difundir sistemáticamente su carácter perverso y despiadado. Sus medios, estrategias y procedimientos se organizaron en función del enemigo así identificado; es decir, se dirigieron a combatirlo a ultranza y a prevenir las amenazas que eventualmente pudiera representar. Así se configuró en la PDSD: "La antípoda de la política democrática es el terrorismo, que pretende imponer por la violencia su voluntad sobre los otros, al costo de la vida de miles de civiles... Frente al terrorismo sólo puede haber una respuesta: derrotarlo" (Presidencia de la República, Ministerio de Defensa Nacional, 2003, p. 5).

La estrategia inmediata luego del fracaso de los diálogos con las Farc en 2002 implicó, en primera instancia, producir sobre el enemigo una verdad que volviera totalmente legítima, urgente y necesaria la guerra sin tregua contra este. ${ }^{7} \mathrm{El}$ resultado efectivo de ello fue denegar al grupo armado el estatus de beligerancia y, por

6 Así, coincido con Castro-Gómez (2010, p. 34) cuando afirma que la racionalidad de las prácticas consiste en el diseño de "unos objetivos hacia los cuales debe ser dirigida la acción, la utilización calculada de unos medios para alcanzar esos objetivos y la elección de unas determinadas estrategias que permitirán la eficaz articulación entre medios y fines o, en su defecto, el uso de los efectos imprevistos para un replanteamiento de los propios fines".

7 Tomo en cuenta investigaciones que analizaron el carácter ético y autojustificativo de los discursos bélicos (Foucault, 2000; Negri y Hard, 2001; Walzer, 2001). También los abordajes colombianos sobre los discursos retóricos (Uribe y López, 2010) y emocionales (Bolívar, 2006) como estrategias políticas y autojustificativas de la guerra. 
el contrario, atribuirle el de terrorista. ${ }^{8}$ Esta producción del enemigo total se efectuó en la articulación de los ámbitos nacional e internacional. Se articuló una red global de prácticas de gobierno emergentes, cuya tecnología principal fue la seguridad y cuya estrategia fue la guerra preventiva, que comenzaron a liderar los Estados Unidos en varios frentes del planeta, luego del derrumbe de sus torres gemelas. La conexión entre las políticas de seguridad nacional colombianas y las del país norteamericano se enmarca en la histórica y estrecha alianza de cooperación diplomática, económica y militar entre ambos países, que con el fin de combatir el narcotráfico se expresó a finales de la década de 1990 en el Plan Colombia (Presidencia de la República, 1999). Trascurridos pocos días después de los ataques mencionados, el gobierno estadounidense, en el marco de su nueva Estrategia de Seguridad Nacional (Bush, 2002), incluyó dentro de su lista global de terroristas a los grupos insurgentes colombianos. ${ }^{9}$ Finalmente, el entonces presidente Bush logró que el Congreso de su país aprobara que el gobierno colombiano usara el presupuesto del Plan en la guerra interna. También se articularon, en el nivel internacional, las Resoluciones 1368, 1373 y 1377 del Consejo de Seguridad de la Organización de Naciones Unidas (ONU, 2001); ${ }^{10}$ y en los niveles regional y subregional, la Convención Interamericana contra el Terrorismo (OEA, 2002) y el Compromiso de Lima (Comunidad Andina, 2002).

Esta articulación reforzó la polarización y legitimó prácticas coactivas y represivas como forma de gobierno, incluso a través de medidas jurídicas tendientes a desconocer la oposición política y a reducir cualquier indicio de esta a una inequivoca señal de cooperación con el terrorismo. Validó, en últimas, el discurso que ganó

8 Coincido con variados analistas (Ramírez, 2001; Rojas, 2002; Tickner y Pardo, 2003; Tickner, 2006) cuando denominan esta coyuntura como la "terrorización" del conflicto armado interno en Colombia.

9 "En Colombia, reconocemos los vínculos entre los grupos terroristas y extremistas que desafían la seguridad del Estado y las actividades de tráfico de drogas que ayudan a financiar las operaciones de estos grupos. Estamos trabajando para ayudar a Colombia a defender sus instituciones democráticas y derrotar los grupos armados ilegales” (Bush, 2002: 10, traducción propia).

10 En su conjunto, estas resoluciones del Comité contra el Terrorismo del Consejo de Seguridad se enmarcan en la condena internacional de los ataques del 9/11. Declaran que el terrorismo constituye en el siglo XXI una grave amenaza para la paz y la seguridad internacionales y un desafío para toda la humanidad, y afirman la necesidad de un esfuerzo sostenido e integral de todos los Estados miembros para prevenir y reprimir cualquier acto de este tipo, mediante la restricción de sus fuentes de financiación y de la circulación de terroristas a través de las fronteras internacionales (ONU, 2001). 
una creciente y definitiva aceptación electoral durante la campaña presidencial de 2002, el cual estableció la necesidad de un estatuto antiterrorista "que facilite la detención, la captura, el allanamiento", y sentenció que "cualquier acto de violencia por razones políticas o ideológicas es terrorismo" (Uribe, 2002, punto 33).

Más allá de lo inaceptables y condenables que resultaron los efectos de la polarización del conflicto armado interno, que siempre serán producto de la corresponsabilidad entre las fuerzas militares enfrentadas, los mismos fueron usados estratégicamente para justificar las medidas y los procedimientos mediante los cuales se procuró ganar la guerra. El caso paradigmático de ello fue el reiterado uso retórico de la práctica del secuestro de civiles por parte de las Farc y otros grupos armados, para justificar medidas jurídicas de excepción, tales como el Decreto del Estado de Conmoción Interior (Presidencia de la República, 2002, 11 de agosto), que suspendió parte del orden constitucional vigente. Como parte de la polarización, dicha justificación siempre se efectuó desde una moral heroica y combativa, cuyo proyecto épico fue derrotar el enemigo y, asimismo, defender la población. No obstante, como se detalla en el siguiente apartado, en nombre de la protección de la población terminaron por suspenderse algunos de sus derechos fundamentales.

\section{Garantizar la soberania}

El fin de esta racionalidad fue recuperar y ampliar el dominio estatal sobre el territorio nacional, especialmente sobre las zonas del país que históricamente carecieron de la presencia institucional del estado y sobre aquellas en las que dicha presencia fue disputada por los grupos armados insurgentes, en algunas de las cuales predominó el gobierno de facto de las Farc. Los objetivos estratégicos para alcanzar este fin consistieron en aumentar el tamaño de las fuerzas armadas del estado, mejorar su capacidad técnica y militar y desplegar su presencia por todo el territorio nacional. Entre los procedimientos ejecutados para realizar estos objetivos, el citado 
decreto que declaró el estado de conmoción interior estableció el incremento de las fuerzas militares, el aumento y mejoramiento de su capacidad técnica, así como el fomento de su exaltación y apoyo moral incondicional para ganar la guerra. ${ }^{11}$ De forma complementaria, el Plan Nacional de Desarrollo 2003-2006 (Congreso Nacional de la República, 2003) garantizó el presupuesto necesario para el crecimiento militar y trazó como meta del cuatrienio "contar con un total de 160000 soldados, entre regulares, campesinos y profesionales, y 100000 policías". Al final del mismo cuatrienio, el pie de fuerza de las Fuerzas Militares y de Policía presentó, en conjunto, un incremento del 36 \% (DNP, 2007). Este logro favoreció la recuperación del dominio territorial de zonas del país que antes carecían por completo de presencia permanente de fuerza pública. Sin embargo, lo que se presentó como el más notable logro de la PDSD, significó un lamentable y creciente proceso de militarización social.

La racionalidad se efectuó en una serie de medidas normativas que facilitaron procedimientos y acciones militares, policiales y de inteligencia, sin mediación judicial, dirigidas estratégicamente a desarticular la presencia de las Farc en sus territorios de influencia y romper los vínculos que este grupo pudiera tener con la población. La estrategia específica consistió en custodiar el territorio, vigilar a las personas, allanar los domicilios de quienes levantaran sospecha o fueran señalados de ser auxiliadores de los grupos terroristas y, en general, restringir la entrada y salida de los territorios, esto es, controlar la circulación de personas y vehículos. ${ }^{12}$

Nuevamente la justificación de estas medidas y estrategias apeló a retóricas morales y emocionales que perfilaron una situación

${ }^{11}$ Este último fue un eje retórico y emocional clave del discurso de posesión presidencial en 2002, registrado por la revista Semana (2002, 7 de agosto): "Apoyaré con afecto a las Fuerzas Armadas de la Nación y estimularemos que millones de ciudadanos concurran a asistirlas".

12 El Decreto del estado de conmoción interior (137 de 2002) estipula que: “... en las circunstancias de excepción que vive el país se requiere que las autoridades adopten medidas tendientes a restringir la libre circulación de personas y vehículos en aquellos lugares y horas determinados por las autoridades respectivas [y a] establecer mecanismos jurídicos para operar eficazmente en contra de la delincuencia organizada facilitando la aprehensión, captura y retención de los eventuales implicados; realizando allanamientos e interceptaciones, identificando sospechosos y recogiendo pruebas que conduzcan a establecer la responsabilidad de autores y partícipes. Así mismo asegurar que dichos mecanismos jurídicos contribuyan a la eficacia de la investigación y juzgamiento de conductas terroristas" (Presidencia de la República, 2002, agosto 11, decreto 1837). 
crítica de amenaza extrema a la soberanía del estado, especialmente en cabeza de sus representantes a nivel regional y local:

se han dedicado los grupos armados a la vil empresa de amenazar los legitimos representantes de la democracia regional, los gobernadores, los alcaldes, diputados y concejales y sus colaboradores, intentando la ruina de nuestras instituciones, sembrando la anarquía y creando la sensación de orfandad, abandono y desgobierno en amplias zonas del país. (Presidencia de la República, 2002)

Garantizar la soberanía aparece aquí como una racionalidad apocalíptica que crea una suerte de condiciones morales y éticas a partir de las cuales pareciera que no se puede rechazar la imperiosa necesidad de un régimen jurídico de excepción que permita el restablecimiento de la soberanía del estado y, en consecuencia, termina naturalizándose como una medida necesaria, justa y urgente. Además de ello, dicho régimen se justificó por el reconocimiento de "la debilidad del Estado para contrarrestar eficientemente estas acciones terroristas e impedir la extensión de sus efectos, con los recursos que el derecho ordinario ha previsto para una Nación en estado de relativa calma" (Presidencia de la República, 2002, agosto 11, decreto 1837).

En efecto, con el decreto del estado de conmoción interior (Presidencia de la República, 2002, agosto 11, decreto 1837) y el que estableció las medidas para el control del orden público (Presidencia de la República, 2002, septiembre 9) se constató el uso bélico de la soberanía jurídica del Estado, en la medida en que ambos procedimientos normativos tuvieron la potestad de suspender las garantías jurídicas que se consideraron necesarias, incluidas las de quienes se señalaron como sospechosos de terrorismo. ${ }^{13}$ Esto significó que el derecho y la ley fueron de hecho recursos que se usaron como estrategia de gobierno en medio de la guerra, y simultáneamente, como arma de guerra que hizo efectiva unas finalidades específicas

\footnotetext{
${ }^{13}$ Este análisis coincide con Agamben (2004) cuando afirma que la instauración de los estados de excepción abre la posibilidad de suspender la soberanía política de los vivientes con el fin paradójico de restablecer un orden soberano que se percibe amenazado o vulnerado, pero que termina dejando en estado de indefensión a cierta porción de asociados de dicho orden.
} 
de gobierno, basadas en la dominación, la represión y el control. De manera que el régimen jurídico y el conjunto de sus mecanismos pudieron en un momento dado, y una vez diagnosticada la situación de crisis social e institucional o identificada una amenaza terrorista, suspender las garantías que se supone aquellos custodian, con el fin mayor de salvaguardar el poder de soberanía, la conservación del orden público, la defensa de la población y la preservación del dominio sobre el territorio nacional. ${ }^{14}$ En medio de la guerra, la preservación de la soberanía del Estado se efectúa a toda costa, a través de los medios que sean necesarios, incluso a costa de la ley y de la restricción de las libertades de algunos de sus asociados.

Las condiciones de aceptabilidad de estas medidas se juegan, entonces, en convencer públicamente acerca de la necesidad, la urgencia, la inevitabilidad y la justicia del régimen jurídico de excepción como estrategia de guerra. Y la racionalidad empleada para ello es la normalización de las medidas de excepción como única alternativa que puede llegar a garantizar la soberanía del Estado sobre todo el territorio nacional, y especialmente sobre las zonas de rehabilitación y consolidación. ${ }^{15}$

Sin embargo, la aceptabilidad no solo se jugó con respecto al régimen jurídico de excepción como estrategia de dominación y represión, sino también con respecto a una suerte de márquetin turístico dirigido a promover en la población el deseo y la práctica de viajar por las carreteras del territorio nacional durante las vacaciones y los días feriados. Así, la campaña "Vive Colombia, viaja por ella" (Presidencia de la República, Ministerio de Comercio, Industria y Turismo, 2002) ${ }^{16}$ se convirtió en una importante estrategia de recuperación de la soberanía sobre el territorio nacional, que contó

${ }^{14}$ Este análisis coincide con Foucault (2006) cuando muestra cómo el mecanismo de salvaguarda del Estado puede eventualmente desencadenar prácticas de coacción, de suspensión de libertades o, en última instancia, de supresión de la vida a fin de asegurar la conservación del Estado y su estabilidad y orden interior.

${ }^{15}$ El régimen excepcional establecido para el control de estas zonas restringió el derecho de circulación y residencia a través de medidas como: "el toque de queda, retenes militares, indicativos especiales para la movilización, permisos especiales para el libre tránsito, circulación o permanencia restringida o prohibida de personas o vehículos en horas y lugares determinados" (Presidencia de la República, 2002, 9 de septiembre)

${ }^{16}$ Criscione y Vignolo (2014) analizan el turismo promovido durante el periodo investigado como un dispositivo de movilidad e identidad nacional, que operó notablemente en medio de la guerra. 
con la participación conjunta de la población civil y efectivos del Ejército Nacional y la Policía de Carreteras. El papel de las Fuerzas Armadas consistió en garantizar la seguridad de las caravanas turísticas hacia zonas en las que se practicaba el secuestro de civiles por parte de las Farc.

\section{Gestionar una población favorable a la guerra}

El fin que movilizó esta racionalidad fue promover diferentes formas de participación voluntaria y comprometida de la población, de forma directa o indirecta, en los objetivos y las estrategias que organizaron la guerra. Los objetivos para lograr dicho fin consistieron en suscitar sentimientos colectivos de identidad nacional, promover la percepción de necesidad e inevitabilidad de la guerra, estimular la aceptación pública de la empresa bélica, incitar el repudio nacional del enemigo interno, despertar la admiración de la creciente capacidad militar de las fuerzas armadas del estado y la vocación heroica de sus soldados, y solicitar para estos apoyo moral incondicional por parte de la población. Todo esto fue posible en virtud de una suerte de sinergia entre diferentes prácticas: los estímulos económicos para la vinculación voluntaria de soldados campesinos, el programa de recompensas y las redes de informantes y cooperantes, la iniciativa privada de algunos medios de comunicación y sectores empresariales, la reiteración y masificación de diferentes campañas publicitarias y la movilización ciudadana a través de manifestaciones en el espacio público (dentro de las que se incluyen las ya mencionadas caravanas turísticas).

La gestión mediática de la guerra y de su aceptabilidad pública fue evidente en el seguimiento periodístico de la campaña presidencial de 2002 por parte de la revista Semana. Una mirada minuciosa y analítica ${ }^{17}$ a las ediciones publicadas entre el 17 de diciembre de

\footnotetext{
${ }^{17}$ El análisis que sigue se basa en la concepción performativa de la realidad (Butler, 2002), según la cual interpreto que las imágenes y el discurso que las enmarca revisten un poder que no es solo simbólico, sino ante todo material y político. También en la concepción de la publicidad como procedimiento de gestión de la opinión pública, que involucra la producción de verdad o "veridicción" (Foucault, 2006). Y, finalmente, en el concepto de interpelación (Althusser,
} 
2001 y el 20 de mayo de 2002, víspera de la elección presidencial, pone en evidencia no solo el proceso creciente de polarización social y política que precipitó el fracaso de los diálogos con las Farc y reactivó la guerra, sino el papel de este medio de comunicación en dicho proceso. Este papel se materializó específicamente en la manera como la portada de la edición número 1028 de la revista (Semana, 2002, enero 14-21) interpeló a la opinión pública nacional: su propuesta visual, alarmante y dramática, abrió la posibilidad de la guerra mediante una pregunta superlativa en letra mayúscula (¿CÓMO SERÍA UNA GUERRA TOTAL?), que abarcó la totalidad del espacio destinado a la portada y usó el contraste cromático para destacar las letras rojas que conformaron las dos últimas palabras, las cuales fueron rasgadas y resquebrajadas por una bala que las atravesó. El artículo principal de esta edición retomó esta pregunta, con un sugestivo fondo camuflado, para afirmar que "en medio del póker de Pastrana y las Farc ese es el interrogante en la mente de los colombianos". Con ello, la revista presupuso performativamente la preocupación de la población colombiana, e instauró la guerra como una materialidad inminente y una verdad incuestionable. A su turno, el artículo inmediatamente posterior se preguntó por la capacidad militar de las Fuerzas Armadas colombianas para enfrentar a las Farc y afirmó que en definitiva dicha capacidad se fortaleció notablemente gracias a los aportes financieros y técnicos del Plan Colombia, pese a que aún no se había aprobado oficialmente su uso en la inminente campaña bélica contra ese grupo armado.

Ya en una edición anterior de la revista (Semana, 2001, diciembre 17-24) se había comenzado a barajar este inminente escenario bélico, en particular, mediante un artículo que describió el crecimiento significativo del poder de la Fuerza Aérea Colombiana gracias a los aportes económicos, militares y tecnológicos del mencionado Plan, y afirmó que ello significó en el rumbo de la guerra un giro definitivo a favor de las fuerzas del Estado. El artículo se acompañó de una foto que encuadra a un grupo de pilotos bajo la pregunta “¿quiénes son estos valientes hombres?”. En efecto, además

2003), entendido como el llamado de atención que se efectúa desde una posición de poder y la eventual acogida por parte de los sujetos frente a tal convocatoria. 
de generar la percepción de necesidad e inevitabilidad de la guerra y promover su aceptación por parte de la opinión pública, con este tipo de artículos la revista buscó despertar en su público la admiración por la creciente capacidad militar de las Fuerzas Armadas y la vocación heroica de sus soldados. Este llamado a la admiración mediante la exaltación del heroísmo también fue evidente en la portada de la edición 1031 (Semana, 2002, febrero 4-11), la cual presentó el fotomontaje de plano medio que combinó la imagen de Superman y la novedosa y "audaz" figura del candidato que sorpresivamente comenzó a encabezar las encuestas de opinión que midieron la intención de voto durante el proceso preelectoral. De esta singular manera, el candidato fue promovido en el público como el gran héroe destinado a salvar la patria de las amenazas que la asechan, haciendo eco de su ya referida autopresentación como primer soldado héroe de la Nación.

El mismo llamado a la admiración, y quizás al compromiso moral y la identificación emocional, se configuró en las imágenes, las consignas y los videos de la campaña publicitaria del Ejército Nacional de 2007, denominada "Los héroes en Colombia ¡Sí existen!" (Ejército Nacional de Colombia, s.f.). Su efecto performativo se realizó a través de la repetición sistemática, ritualizada y exaltada de situaciones extremas, actos heroicos, enunciados estoicos e imágenes inhóspitas donde los soldados le hablan a la población con tono persuasivo y familiar. De este modo se promueven el compromiso moral y la vinculación afectiva del público con lo héroes masculinos destinados a salvar la patria y a sacrificarse a cualquier costo en la empresa bélica. ${ }^{18}$

Bajo esta racionalidad, la eventual vinculación de la población con la campaña bélica no se efectúa mediante vigilancia, coacción o represión, como ocurría bajo las dos racionalidades anteriores. Por el contrario, se produce de manera voluntaria y hasta entusiasta

\footnotetext{
${ }^{18}$ La voz en off de una de las propagandas dice: "Nuestros héroes están en el cielo, para darte tranquilidad en tierra / Recorren las frías montañas, para que disfrutes en familia el calor de hogar / Nunca se detienen, para que tú puedas descansar. / Permanecen despiertos, para que tus hijos sueñen un mejor país. / Estas fiestas disfrútalas en paz y tranquilidad, nuestros héroes están para protegerte. / Los héroes en Colombia ¡Sí existen!” (Ejército Nacional de Colombia, s.f.)
} 
y orgullosa, gracias al descubrimiento virtual, pero con efecto de realidad, de los soldados de la patria en su tarea de custodiar las libertades y garantizar la tranquilidad de la población colombiana. De este modo la publicidad se convierte en el principal recurso para gestionar un público que acepte y desee la guerra, e incluso para convocar a la población a manifestar masiva y públicamente su fe en la causa bélica, su apoyo moral a los soldados del Ejército Nacional y su repudio a las Farc. La primera manifestación de este tipo ocurrida durante el periodo investigado fue registrada en la edición 1031 de Semana (2002, febrero 4-11) con un sugestivo titular: "El 'cacerolazo' a las Farc muestra que crece la exigencia popular a la guerrilla para que no ataque a la población civil" y abandone su histórica práctica de secuestro de civiles, la cual había aumentado por cuenta del recrudecimiento de la guerra a inicios de 2002.

Este tipo de manifestaciones de repudio al grupo armado se efectuó a nivel municipal y en principio fue de carácter local. Sin embargo, la confluencia de varias manifestaciones como estas a lo largo y ancho del país derivaria, seis años más tarde, en la que quizás ha sido la manifestación nacional e internacional más multitudinaria jamás registrada en la historia del país: la marcha contra las Farc, durante la cual "en las calles del mundo entero millones de personas le gritaron a las Farc 'No más secuestros, no más violencia" ("En las calles del mundo", 2008). Aunque la misma fue gestionada a través de los medios de comunicación privados, su convocatoria comenzó como una iniciativa ciudadana a través la red social Facebook. Sin embargo, la consigna "Colombia soy yo", que movilizó la marcha, provenía de una campaña publicitaria oficial de fortalecimiento de la identidad nacional lanzada en el año 2002, cuya consigna, "iSiente tu bandera, cree en tu país!", fue promocionada en la revista Semana (“iSiente tu bandera...!”, 2002). 


\section{Asegurar la inversión transnacional}

El fin que orienta esta racionalidad es garantizar la confianza inversionista y la movilidad segura de los capitales trasnacionales a lo largo y ancho del territorio nacional. Los objetivos para realizar tal fin consistieron en custodiar la infraestructura (maquinaria, oleoductos, redes eléctricas, redes viales, etc.), defender la misma de eventuales atentados o daños, prevenir el asalto a la propiedad privada, contrarrestar las amenazas a las libertades individuales, eliminar las restricciones a la movilidad $^{19}$ y eventualmente reprimir las protestas sociales y sindicales que entorpezcan los procesos productivos y empresariales; todo ello mediante la oportuna acción militar y policial:

El Gobierno Nacional está desarrollando programas especiales para prevenir los ataques terroristas contra la infraestructura carbonífera, eléctrica, petrolera, de puertos y aeropuertos y de telecomunicaciones, asi como para prevenir el robo de hidrocarburos, mediante el trabajo coordinado en estructuras de apoyo del Ejército, la Fiscalía, el DAS, la DIJIN. (Presidencia de la República, Ministerio de Defensa Nacional, 2003, punto 126)

Se trata, en efecto, de una racionalidad neoliberal ${ }^{20}$ en la medida en que los objetivos y todos los procedimientos gubernamentales se orientan a garantizar las condiciones de seguridad idóneas para el ejercicio de la libre competencia y la libre circulación de capitales de todo tipo: humanos, sociales, culturales, simbólicos, económicos. Y ello en el marco de una relación de tensión paradójica entre producción y destrucción de libertades. Esto implica que para que pueda darse el libre juego de los intereses económicos, la libre circulación de los capitales, el libre flujo de las inversiones y la libre dinámica del emprendimiento, esto es, el libre imperio de la econo-

\footnotetext{
19 "El imperio de la ley es también garantía de desarrollo y prosperidad económica. Cada vez que hay un secuestro se afecta profundamente la confianza de los inversionistas, se dispersan los capitales y se pierden fuentes de empleo." (Presidencia de la República, Ministerio de Defensa Nacional, 2003, p. 7)

${ }^{20}$ Esta afirmación debe entenderse en el marco de la analítica de la gubernamentalidad liberal y neoliberal que Foucault (2007) desarrolló en su curso Nacimiento de la biopolítica. Se descartan, por tanto, las interpretaciones que explican el neoliberalismo desde la ideología y también aquellas que lo explican exclusivamente desde variables económicas o de clase social.
} 
mía neoliberal, se imponen como necesarias una serie de medidas que aseguren las condiciones adecuadas que faciliten y garanticen dichas libertades. Y no se trata precisamente de las libertades concebidas desde el enfoque de derechos o desde la soberanía política de los ciudadanos, sino de libertades económicas: de movilidad, de inversión, de utilidad, de interés, de consumo. El límite y a la vez la finalidad del gobierno está definido por el principio radical y total de la libre competencia de mercado, por tanto, todos los procedimientos consisten en adecuar la práctica gubernamental al libre juego del mercado y los intereses económicos.

De tal forma que la finalidad de la práctica gubernamental deja de ser el control del territorio y la recuperación de la soberanía nacional en sí mismos, y adquiere la función prioritaria de gestionar la confianza inversionista y asegurar la inversión económica. Esto quiere decir que, bajo esta racionalidad gubernamental, el control del territorio ya no es solo un objetivo de soberanía sino, ante todo, y por encima de este, un objetivo económico y de mercado. Desde esta perspectiva, no basta con implementar las estrategias de guerra si estas no se combinan con un saber sobre el funcionamiento natural del mercado, sus regularidades y variaciones, puesto que es la única manera de no oponérsele sino, al contrario, procurar su gestión, maximizar sus utilidades y proteger los intereses en juego.

Como en las otras racionalidades bélicas analizadas, esta también funciona de acuerdo con un particular procedimiento de veridicción que ya no es de tipo jurídico, para efectuar medidas de excepción que garanticen la soberanía; ni tampoco de tipo mediático, para gestionar el consentimiento social de la guerra; sino de tipo económico, que produce garantías de inversión y evalúa los costos económicos del terrorismo. En la tabla 1 puede verse el balance de los costos que en el 2001 fueron causados por los ataques sistemáticos a la infraestructura energética, vial y de comunicaciones. 


\begin{tabular}{|l|r|}
\hline \multicolumn{1}{|c|}{ Sector } & \multicolumn{1}{|c|}{$\mathbf{2 0 0 1}$} \\
\hline Hidrocarburos $^{21}$ & 1241260000000 \\
\hline Eléctrico $^{22}$ & 292322 \\
\hline Transporte terrestre $^{23}$ & 2554500000 \\
\hline Transporte ferroviario $^{24}$ & 1732000000 \\
\hline Transporte aéreo $^{25}$ & 703000000 \\
\hline Total nacional & 1538571500000 \\
\hline
\end{tabular}

Tabla 1. Costos por terrorismo y acciones delincuenciales contra

la infraestructura nacional en millones de pesos

Fuente: información tomada del Plan Nacional de Desarrollo

2002-2006 (DNP, 2003, p. 36).

Aquí la racionalidad de gobierno ya no se juega en el nivel de la soberanía nacional o en el de la opinión pública (las cuales sin duda son condiciones necesarias pero no suficientes) sino en la gestión de la seguridad para la inversión trasnacional. El mercado se propone, entonces, como un ámbito y un mecanismo de formación de la verdad necesaria para orientar la práctica de gobierno. Al mercado, es necesario dejarlo trascurrir para solo gobernarlo con la racionalidad de la menor intervención posible, pues solo así, en su libre flujo, formula su propia verdad y se instaura como regla y norma de la práctica gubernamental. La veridicción económica consiste, por tanto, en calcular el costo de producción de la libertad, e implica determinar con exactitud en qué medida y hasta qué punto el interés individual, los diferentes intereses en juego, individuales en cuanto divergen unos de otros y eventualmente se oponen, no constituyen un peligro para el interés de todos.

${ }^{21}$ Corresponde a robo de combustible, contrabando, mezclas ilícitas y atentados a oleoductos y gasoductos. El robo de combustible incluye los costos totales para la nación, es decir, las pérdidas de Ecopetrol, la sobretasa, el impuesto global y el IVA. La cifra aproximada de pérdida es de $\$ 900000$ millones anuales. El monto adicional corresponde a los 170 atentados perpetrados contra el oleoducto Caño Limón-Coveñas (\$265000 millones) y los costos de reparación de gasoductos (\$ 6400 millones) (Colombia, DNP, 2003).

22 Voladura de torres de energía (Colombia, DNP, 2003).

${ }^{23}$ Atentados a puentes y peajes. No incluye pérdidas por reducción de tráfico de vehículos.

${ }^{24}$ Atentados contra la red férrea.

25 Atentados que afectaron radares, radio ayudas, electromecánicos y aeropuertos. 
Finalmente, asegurar el capital transnacional y garantizar la confianza inversionista es una racionalidad que oscila tensa y paradójicamente entre el gobierno económico y el gobierno bélico: la intervención gubernamental en la economía solo se desencadenará cuando esta resulte útil en términos de proteger los intereses en juego -y ya no los derechos-. La utilidad y, sobre todo, el interés son justamente los criterios de la autolimitación inmanente de esta racionalidad gubernamental que, en efecto, oscila entre la modalidad económica y la modalidad bélica. Este es el escenario gubernamental contemporáneo en el que se juega la gestión de la seguridad en Colombia.

\section{Alcances del análisis de racionalidades}

El análisis de las cuatro racionalidades permite reconocer críticamente la manera como en Colombia la guerra se desplegó como una modalidad específica de gobierno de la población durante la primera década del presente siglo, justo después de la última tentativa de negociación política con las Farc entre 1998 y 2001. Ello lo convierte en un ejercicio de memoria histórica que pone en evidencia cómo se desplegó una red articulada de prácticas de gobierno que radicalizó la guerra, gestionó una población que la aceptó incondicional y hasta apasionadamente, y convirtió la aventura bélica en el principal motivo de la colombianidad y el orgullo patrio. Y en general, en una invitación a reconocer la guerra en Colombia como racionalidad de gobierno y, a la vez, a descifrar las racionalidades de gobierno que en el país se desplegaron de manera efectiva en medio y a través de la guerra durante el periodo considerado.

Pero el alcance de este análisis no solo radica en la capacidad de evidenciar críticamente los mecanismos y las estrategias de perpetuación y normalización de la guerra durante la primera década del siglo, sino que reside también en reconocer los desafios que actualmente enfrentamos en Colombia para avanzar hacia la finalización definitiva del conflicto armado. 
Uno de los desafios se relaciona justamente con la necesidad de desarticular la racionalidad que tiene como fin polarizar el conflicto. El reciente proceso de negociación entre el gobierno nacional y las Farc para terminar la guerra inició en 2012, se extendió por cinco años y estuvo atravesado por un tenso clima de polarización social y política, que amenazó permanentemente el logro de los acuerdos, su refrendación y aún actualmente su implementación. Por ello, hoy más que nunca es necesario superar esta racionalidad, puesto que es el principal obstáculo para implementar el acuerdo sobre participación política de las Farc. Si esta organización y sus miembros no dejan de ser vistos como el enemigo interno de la Nación, si no se valoran los avances en el proceso de su desarme y si no se los empieza a reconocer como nuevos y legítimos actores políticos, no será posible su cabal integración en la vida política del país. Por el contrario, crecerá su estigmatización, continuará su persecución y hasta se efectuará su exterminio, como desafortunadamente lo constata la creciente cifra de asesinatos de líderes sociales y políticos en regiones del país que registraron una histórica presencia de las Farc.

Otro desafio íntimamente relacionado con el anterior tiene que ver con el papel del Estado y el sector empresarial, especialmente los medios masivos de comunicación, en la gestión de una opinión pública favorable a la implementación de todos los acuerdos de paz firmados y refrendados recientemente. Ello implica no solo superar históricamente el consentimiento social de la guerra como vía normalizada para resolver los conflictos políticos, económicos y sociales (que fue el objetivo que movilizó la tercera racionalidad), sino también, y sobre todo, promover en la población la creación y proliferación localizada de prácticas y culturas de paz.

\section{Referencias}

Agamben, G. (2004). Homo Sacer II. Estado de excepción. Valencia: Pre-Textos.

Althusser, L. (2003). Ideología y aparatos ideológicos de Estado. Freud y Lacan. Buenos Aires: Nueva Visión. 
Bolivar, I. (2006). Discursos emocionales y experiencias de la politica. Las FARC y AUC en los procesos de negociación del conflicto (1998-2005). Bogotá: Uniandes, CESO.

Bush, G. (2002). The National Security Strategy of the United States of America. Recuperado de http://www.globalsecurity.org/military/library/policy/ national/nss-020920.pdf

Butler, J. (2002). Cuerpos que importan. Sobre los limites materiales y discursivos del "sexo". Buenos Aires: Paidós.

Castro-Gómez, S. (2010). Historia de la Gubernamentalidad. Razón de Estado, liberalismo y neoliberalismo. Bogotá: Siglo del Hombre.

¿Cómo sería una guerra total? En medio del póker entre Pastrana y las Farc ese es el interrogante en la mente de los colombianos. (2002, enero 14-21). Semana, 1028, pp. 18-25.

Comunidad Andina. (2002, junio 17). Compromiso de Lima: Carta Andina para la paz, la seguridad, limitación y control de los gastos destinados a la defensa externa. Recuperado de http:/ /www.comunidadandina.org/documentos/actas / compromiso_lima.htm

Congreso Nacional de la República. (2003, junio 26). Ley 812 de 2003, por la cual se aprueba el Plan Nacional de Desarrollo 2003-2006, hacia un Estado comunitario. Recuperado de http://www.dnp.gov.co/PortalWeb/Portals/0/ archivos/documentos/GCRP/PND/Ley_812.pdf

Criscione, G. y Vignolo, P. (2014). ¿Del terrorismo al turismo? "Vive Colombia, viaja por ella" como dispositivo de movilidad, entre conflicto armado y patrimonio cultural. En M. Chaves, M. Montenegro y M. Zambrano (Comps.), El valor del patrimonio: mercado, politicas culturales y agenciamientos sociales (pp. 473517). Bogotá: Instituto Colombiano de Antropología e Historia.

DNP - Departamento Nacional de Planeación. (2003). Plan Nacional de Desarrollo (2002-2006). Hacia un Estado comunitario. Recuperado de http:/ / www.dnp.gov. co/PortalWeb/Portals/0/archivos/documentos/GCRP/PND/PND.pdf 
DNP - Departamento Nacional de Planeación. (2007). Plan Nacional de Desarrollo (2006-2010). Estado comunitario: desarrollo para todos, Tomo I. Recuperado de http://www.dnp.gov.co/PortalWeb/LinkClick. aspx?fileticket=WSgQTUkodjQ\%3d\&tabid=65

DNP - Departamento Nacional de Planeación, CONPES - Consejo Nacional de Política Económica y Social. (2007). Politica de consolidación de la Seguridad democrática: fortalecimiento de las capacidades del sector defensa y seguridad, Documento CONPES 3460. Recuperado de http: / /www.dnp.gov.co/PortalWeb/ Portals/0/archivos/documentos/Subdireccion/Conpes/3460.pdf

Ejército Nacional de Colombia. (s.f.). Los héroes en Colombia ;Sí existen! Recuperado de http: / /www.ejercito.mil.co/index.php?idcategoria=228741\&pag=3

El nuevo presidente. (2002, agosto 7). Semana [en línea]. Recuperado de http:/ / www.semana.com/especiales/nuevo-presidente/64756-3.aspx

En las calles del mundo entero millones de personas le gritaron a las Farc "No más secuestros, no más violencia". (2008, febrero 4). Semana [en línea]. Recuperado de http://www.semana.com/on-line/calles-del-mundo-enteromillones-personas-gritaron-farc-no-secuestros-no-violencia/109238-3.aspx

Foucault, M. (1991). El sujeto y el poder. Bogotá: Carpe Diem.

Foucault, M. (1992). Nietzsche, la Genealogía, la Historia. Valencia: Pre-Textos.

Foucault, M. (2000). Defender la sociedad. Curso en el Collège de France (19751976). Buenos Aires: Fondo de Cultura Económica.

Foucault, M. (2006). Seguridad, territorio, población. Curso en el Collège de France (1977-1978). Buenos Aires: Fondo de Cultura Económica.

Foucault, M. (2007). Nacimiento de la biopolitica. Curso en el Collège de France (1978-1979). Buenos Aires: Fondo de Cultura Económica.

Foucault, M. (2009). El gobierno de sí y de los otros. Curso en el Collège de France (1982-1983). Buenos Aires: Fondo de Cultura Económica. 
Guerra: ¿Qué tan listos? Las Fuerzas Armadas son hoy más capaces de enfrentar a la guerrilla, pero aun falta mucho para golpear sus finanzas y derrotar el secuestro. (2002, enero 14-21). Semana, 1028, pp. 28-29.

Halcones de la noche. Los pilotos de combate están cambiando el rumbo de la guerra en Colombia. ¿Quiénes son estos valientes hombres? (2001, diciembre 17-24). Semana, 1024, pp. 58-62.

La Encuesta. (2002, febrero 4-11). Semana, 1031, pp. 26-29.

¡Libertad, libertad! El “cacerolazo” a las Farc muestra que crece la exigencia popular a la guerrilla para que no ataque la población civil. (2002, febrero 4-11). Semana, 1031, pp. 32-33.

Muñoz, D. (2012). Pasiones bélicas. Gestión de la guerra en Colombia en la primera década del siglo XXI. Nómadas, (37), 89-103.

Muñoz, D. (2014). Gubernamentalidad bélica: potencias de un concepto localizado para pensar las guerras contemporáneas. Nómadas, (41), 203-219.

Muñoz-Onofre, D. (2015). Pensar la guerra (en Colombia) más allá de la tanatopolitica. Athenea Digital, 15(4), 61-80.

Negri, T. y Hardt, M. (2001). Imperio. Bogotá: Desde abajo.

OEA - Organización de Estados Americanos. (2002). Convención interamericana contra el terrorismo, Resolución 1840. Recuperado de http://www.oas.org/ juridico/spanish/tratados/sp_conve_interame_contr_terro.pdf

ONU - Organización de Naciones Unidas, Consejo de Seguridad, Comité contra el terrorismo. (2001). Resolución 1368 del 12 de septiembre, Condena de los atentados cometidos el 11 de septiembre contra los Estados Unidos; Resolución 1373 del 28 de septiembre, Creación del Comité contra el Terrorismo; Resolución 1377 del 12 de noviembre, Declaración ministerial sobre la acción mundial para combatir el terrorismo. Recuperado de http:/ /www.un.org/es/sc/ctc/resources / res-sc.html 
Presidencia de la República. (1999). Plan Colombia. Documento Oficial del Gobierno Colombiano sobre el Plan Colombia. Recuperado de http://www. derechos.org/nizkor/colombia/doc/planof.html

Presidencia de la República. (2002, agosto 11). Decreto 1837, por el cual se declara el estado de conmoción interior. Diario Oficial, N. ${ }^{\circ} 44.897$. Recuperado de http://www.secretariasenado.gov.co/senado/basedoc/decreto/2002/ decreto_1837_2002.html

Presidencia de la República. (2002, agosto 11). Decreto 1838, por el cual se crea un impuesto especial destinado a atender los gastos del Presupuesto General de la Nación necesarios para preservar la Seguridad Democrática. Diario Oficial, N. ${ }^{\circ}$ 44.897. Recuperado de http://www.secretariasenado.gov. co/senado/basedoc/decreto/2002/decreto_1838_2002.html

Presidencia de la República. (2002, septiembre 9). Decreto 2002, por el cual se adoptan medidas para el control del orden público y se definen las zonas de rehabilitación y consolidación. Diario Oficial, N. ${ }^{\circ} 44.930$. Recuperado de http://www.secretariasenado.gov.co/senado/basedoc/decreto/2002/ decreto_2002_2002.html

Presidencia de la República, Ministerio de Comercio, Industria y Turismo. (2002). Campaña "Vive Colombia, viaja por ella". Recuperado de http://www. redturs.org/documentos/colombia/documentos/coldoc1.pdf

Presidencia de la República, Ministerio de Defensa Nacional. (2003). Política de Defensa y Seguridad democrática. Recuperado de http: / /www.oas.org/csh/ spanish/documentos/Colombia.pdf

Ramírez, S. (2001). El Plan Colombia. Internacionalización del conflicto y dificultades para la paz. En IEPRI (Ed.), El Plan Colombia y la internacionalización del conflicto (pp. 74-107). Bogotá: Planeta.

Rojas, D. (2002). La política internacional del gobierno de Pastrana en tres actos. Análisis político, 46, 100-115.

¡Siente tu bandera, cree en tu país! (2002, mayo 5-13). Semana, 1044, p. 16. 
¿Súper Álvaro? El cañonazo de Uribe es un grito de indignación contra la guerrilla. ¿Logrará traducirse en un triunfo electoral dentro de 10 semanas? Algunos no descartan la primera vuelta. (2002, febrero 4-11). Semana, 1031, pp. 20-25.

Tickner, A. (2006). La securitización de la crisis colombiana: bases conceptuales y tendencias generales. Revista Colombia Internacional, 60, 12-35.

Tickner, A. y Pardo, R. (2003). En busca de aliados para la "Seguridad Democrática”. La política exterior del primer año de la administración Uribe. Revista Colombia Internacional, 56-57, 64-81.

Uribe, A. (2002). Manifiesto democrático - 100 puntos Álvaro Uribe Vélez. Recuperado de http://www.mineducacion.gov.co/1621/articles-85269_ archivo_pdf.pdf

Uribe, M. y López, L. (2010). Las palabras de la guerra: metáforas, narraciones y lenguajes politicos. Un estudio sobre las memorias de las guerras civiles en Colombia. Medellín: La Carreta.

Walzer, M. (2001). Guerras justas e injustas. Un razonamiento moral con ejemplos históricos. Barcelona: Paidós.

\section{Cómo citar este artículo}

Muñoz-Onofre, D. (2018). Racionalidades de gobierno en medio y a través de la guerra reciente en Colombia. Universitas Humanística, 85, 375-399. https:// doi.org/10.11144/Javeriana.uh85.rgmg 